\title{
Commentary Ventilator-induced lung injury and mechanotransduction: why should we care?
}

Mingyao Liu ${ }^{1}$

${ }^{1}$ Department of Surgery, Faculty of Medicine, University of Toronto, Toronto, Ontario, Canada

Corresponding author: Mingyao Liu, mingyao.liu@utoronto.ca

Published: 26 October 2007

This article is online at http://ccforum.com/content/11/5/168

(c) 2007 BioMed Central Ltd

See related research by Li et al, http://ccforum.com/content/11/5/R89
Critical Care 2007, 11:168 (doi:10.1186/cc6131)

\begin{abstract}
Mechanotransduction holds the underlying mechanisms of ventilatorinduced lung injury. Research on this subject, however, could be difficult for clinicians, especially when results are controversial. A recent study by Li and co-workers is used as an example, to explain how to critically read literatures related to basic science and how to understand the limitation of experimental studies.
\end{abstract}

As a professor in a clinical department, I am privileged to work with many clinician-investigator trainees. Recently, a new clinical research fellow told me that he had been reading many papers in order to decide which research project he should take. The more he reads, the more confused he feels. Many literatures sound contradictory. How to determine their clinical relevance is a challenge. In fact, this challenge is not only to new fellows, but also to experienced researchers.

In this issue of Critical Care, Dr Li and Dr Quinn and their colleagues published a research article [1] exploring the molecular mechanisms of ventilator-induced lung injury (VILI). I would like to use this interesting article as an example, to lead readers who are not experts in this field through a translational process.

Mechanical force-induced signal transduction (mechanotransduction) is responsible for many physiological processes in lung development [2], in maintaining lung functions [3], and in pathological conditions related to lung diseases, such as asthma, chronic obstructive pulmonary disease (COPD), and acute respiratory distress syndrome (ARDS), especially related to VILI [4]. However, very much like the routes in a city, both "good boys" and "bad boys" drive on the same streets. Many signal transduction pathways are shared by both the injury and repair processes.
Neutrophil recruitment and activation is an important mechanism for lung tissue injury, which is mediated by a group of small molecules, namely chemokines, especially a subgroup of C-X-C chemokines. Interleukin-8 (IL-8) is the best example, which has been shown to be up-regulated by mechanical forces in human lung cells [5]. Rodents do not have the IL-8 gene, but produce macrophage inflammatory protein-2 (MIP-2) and other C-X-C chemokines. Mechanical stretch induced MIP-2 in rat lung cells [6]. Increased MIP-2 in murine lung was observed after high volume ventilation by $\mathrm{Dr}$ $\mathrm{Li}$ and co-workers [7]. They further questioned that neutrophil migration is mediated by a signal pathway activated by Akt (also called protein kinase B). They used Akt+/- mice, which have lower expression of Akt-1. They also used a chemical inhibitor to prevent the activation of Akt in mice, prior to their exposure to high volume ventilation and/or hyperoxia. Indeed, they demonstrated less lung damage in these experimental settings. This is very exciting, isn't it? However, it is worth mentioning that the Akt pathway is also critically important for proliferation, survival and migration of cell types other than neutrophiles [8]. Inhibition of this pathway in sepsis related lung injury is detrimental $[9,10]$. The clinical application of this strategy needs to be cautious.

Well, another interesting target is nitric oxide (NO). Based on their recent studies, these researchers suspected that endothelial nitric oxide synthase (eNOS) activation is also part of the mechanisms responsible for VILI. They demonstrated increased phosphorylation of eNOS and also demonstrated that nitric oxide synthase (NOS) inhibitor could attenuate VILI. Increased NOS expression and/or activity have been shown in multiple lung injury models [11] and clinical samples [12]. The outcome of NO related clinical studies, however, is controversial [13], which warns us for further investigation.

ARDS $=$ acute respiratory distress syndrome; COPD = chronic obstructive pulmonary disease; eNOS $=$ endothelial nitric oxide synthase; IL-8 $=$ Interleukin-8; MIP-2 = macrophage inflammatory protein-2; NO = nitric oxide; NOS = nitric oxide synthase; VILI = ventilator-induced lung injury. 
As a clinician you may ask why $30 \mathrm{ml} / \mathrm{kg}$ of tidal volume was used in this study and you may note that oxygen was used for ventilation. These injurious regimens have been less (if at all) used clinically. Are these experimental data really useful? This is really a good question. First of all, as experimental biologists, we always try to create a condition that can give definite answers. For example, after serum starvation, add a growth factor into the culture medium to initiate a signal transduction, or start mechanical stretch on statically cultured cells. These protocols help us to reveal the potential of a biological stimulus on a particular biological process. This strategy has also been adapted to animal studies. On the other hand, this may also explain why many experimental findings did not translate to good clinical practices. As a bench scientist, one should try to simulate clinical conditions as much as possible. Recently, clinically relevant models have been emphasized [14].

After going through this interesting paper critically, what have we learnt? First, good literature review may lead to proposal of a testable hypothesis in VILI. Secondly, the mechanical force-induced signal transduction by injurious ventilation (high tidal volume and high oxygen tension) could activate pathways that are important for normal functions. Thirdly, blocking the transient activation of these pathways could be beneficial. Last but not the least, awareness of the significance and limitation of experimental data are crucial for our knowledge translation.

\section{Competing interests}

The authors have no competing interests.

\section{References}

1. Li L-F, Liao S-K, Lee C-H, Huang C-C, Quinn DA: Involvement of Akt and endothelial nitric oxide synthase in ventilationinduced neutrophil infiltration: a prospective, controlled animal experiment. Crit Care 2007, 11:R89.

2. Liu M, Post M: Invited review: mechanochemical signal transduction in the fetal lung. J Appl Physio/ 2000, 89:2078-2084.

3. Liu M, Tanswell AK, Post M: Mechanical force-induced signal transduction in lung cells. Am J Physiol 1999, 277:L667-683.

4. Han B, Lodyga M, Liu M: Ventilator-induced lung injury: role of protein-protein interaction in mechanosensation. Proc $\mathrm{Am}$ Thorac Soc 2005, 2:181-187.

5. Li LF, Ouyang B, Choukroun G, Matyal R, Mascarenhas M, Jafari B, Bonventre JV, Force T, Quinn DA: Stretch-induced IL-8 depends on c-Jun $\mathrm{NH} 2$-terminal and nuclear factor-kappaBinducing kinases. Am J Physiol Lung Cell Mol Physiol 2003, 285:L464-475.

6. Mourgeon E, Isowa N, Keshavjee S, Zhang X, Slutsky AS, Liu M: Mechanical stretch stimulates macrophage inflammatory protein-2 secretion from fetal rat lung cells. Am J Physiol Lung Cell Mol Physiol 2000, 279:L699-706.

7. Quinn DA, Moufarrej RK, Volokhov A, Hales CA: Interactions of lung stretch, hyperoxia, and MIP-2 production in ventilatorinduced lung injury. J Appl Physio/ 2002, 93:517-525.

8. Luo J, Manning BD, Cantley LC: Targeting the PI3K-Akt pathway in human cancer: rationale and promise. Cancer Cell 2003, 4:257-262.

9. Williams DL, Li C, Ha T, Ozment-Skelton T, Kalbfleisch JH, Preiszner J, Brooks L, Breuel K, Schweitzer JB: Modulation of the phosphoinositide 3-kinase pathway alters innate resistance to polymicrobial sepsis. J Immuno/ 2004, 172:449-456.

10. Wrann CD, Tabriz NA, Barkhausen $T$, Klos A, van Griensven M, Pape HC, Kendoff DO, Guo R, Ward PA, Krettek C et al.: The phosphatidylinositol 3-kinase signaling pathway exerts protective effects during sepsis by controlling C5a-mediated activation of innate immune functions. J Immunol 2007, 178: 5940-5948.

11. Liu M, Tremblay L, Cassivi SD, Bai XH, Mourgeon E, Pierre AF, Slutsky AS, Post M, Keshavjee S: Alterations of nitric oxide synthase expression and activity during rat lung transplantation. Am J Physiol Lung Cell Mol Physiol 2000, 278:L1071-1081.

12. Cardella JA, Keshavjee SH, Bai XH, Yeoh JS, Granton JT, Meade MO, Matte-Martyn A, Waddell TK, Liu M: Increased expression of nitric oxide synthase in human lung transplants after nitric oxide inhalation. Transplantation 2004, 77:886-890.

13. Ichinose F, Roberts JD, Jr., Zapol WM: Inhaled nitric oxide: a selective pulmonary vasodilator: current uses and therapeutic potential. Circulation 2004, 109:3106-3111.

14. Steinberg J, Halter J, Schiller H, Gatto L, Nieman G: The development of acute respiratory distress syndrome after gut ischemia/reperfusion injury followed by fecal peritonitis in pigs: a clinically relevant model. Shock 2005, 23:129-137. 